\section{BMJ Paediatrics Open}

\title{
Initial impact of COVID-19 on paediatric spinal services in Scotland
}

\author{
Matthew Newman (D), Enrique Garrido, Athanasios I Tsirikos
}

To cite: Newman M, Garrido E, Tsirikos Al. Initial impact of COVID-19 on paediatric spinal services in Scotland. BMJ Paediatrics Open 2020;4:e000826. doi:10.1136/ bmjpo-2020-000826

Received 31 July 2020 Accepted 21 October 2020

\section{ABSTRACT}

COVID-19 has affected many National Health Service Scotland services. Our aim is to describe this impact on the Scottish National Spine Deformity Service (SNSDS). All referrals to the SNSDS from 1 January 2020 to 30 June 2020 were analysed and compared with the same period in 2019. There was a $64.3 \%$ decline in referrals during the pandemic to the SNSDS. The mean waiting time to be seen in first clinical appointment for a new referral was 6.5 weeks in 2020 compared with 10.9 in 2019. There were 60 patients still waiting to be seen at the end of the study period.

As hospitals prepared for COVID-19, resources and staff were reallocated to ensure the National Health Service (NHS) was adequately prepared for the expected influx of patients. ${ }^{1}$ The risk of COVID-19 for children appears to be lower than it is for adults, however, as one senior paediatrician commented, children are perversely suffering for the benefit of adults. This can be through abuse, loss of education and worsening health outcomes in other domains. ${ }^{2}$

The Scottish National Spine Deformity Service (SNSDS) takes referrals from all 14 of the Scottish NHS health boards serving a population of approximately 1.5 million children. We analysed the number of new referrals to the SNSDS, and the mean wait time to be seen during the initial period of the COVID-19 pandemic.

From January to June 2020, our service received a total of 155 referrals; a decrease from 238 referrals from the same period in 2019. Of these, 40 referrals to our service came in the months April, May and June 2020. This compares to 112 referrals during the same period in 2019. This represents a 64.3\% decline in referrals comparing April, May and June 2020 to the same period in 2019 (figure 1).

The pandemic had an effect on our mean waiting times for paediatric patients to be first seen by a spinal surgeon. Prior to the pandemic, our mean waiting time for a new patient to be seen in our outpatient clinic was 10.8 weeks. During the first half of 2020 , this waiting time was reduced to 6.5 weeks (figure 2). However, at the time of data collection on the 3 July 2020, there were still 60 patients waiting to be seen in our outpatient clinic who had been referred to the SNSDS within 2020, so it will be some time before we know what the true mean wait time for a new patient is during 2020.

There are several factors that could account for the decline in the number of patients being referred to our service. As some sectors in NHS

\section{Check for updates}

(C) Author(s) (or their employer(s)) 2020. Re-use permitted under CC BY-NC. No commercial re-use. See rights and permissions. Published by BMJ.

Scottish National Spine Deformity Service, RHSC, Edinburgh, UK

Correspondence to Dr Matthew Newman mattynewman87@gmail.com

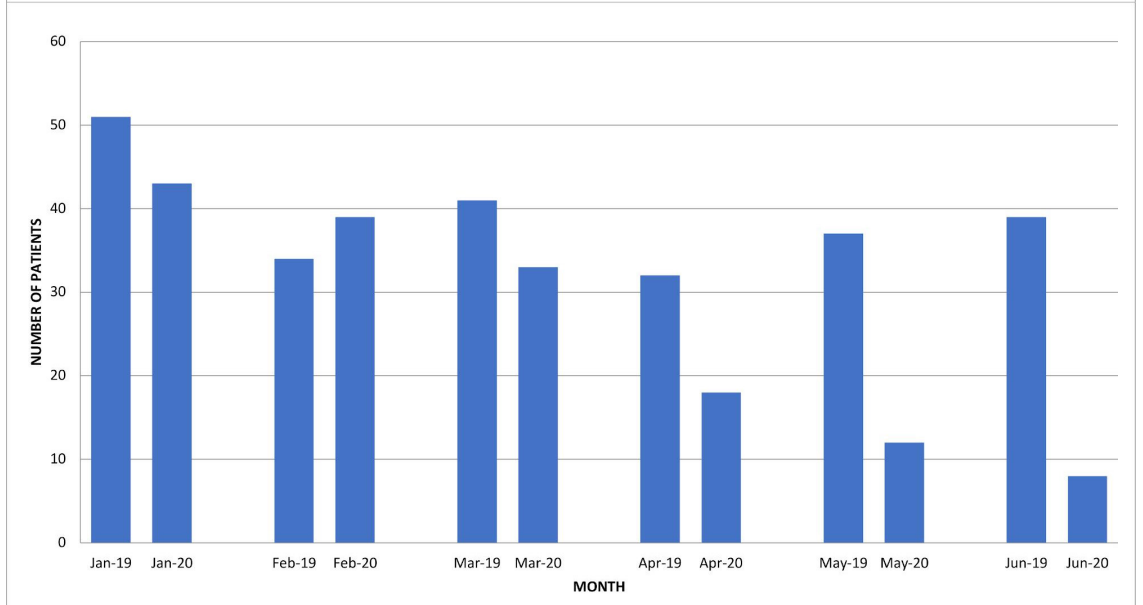

Figure 1 Number of paediatric referrals to the SNSDS. SNSDS, Scottish National Spine Deformity Service. 


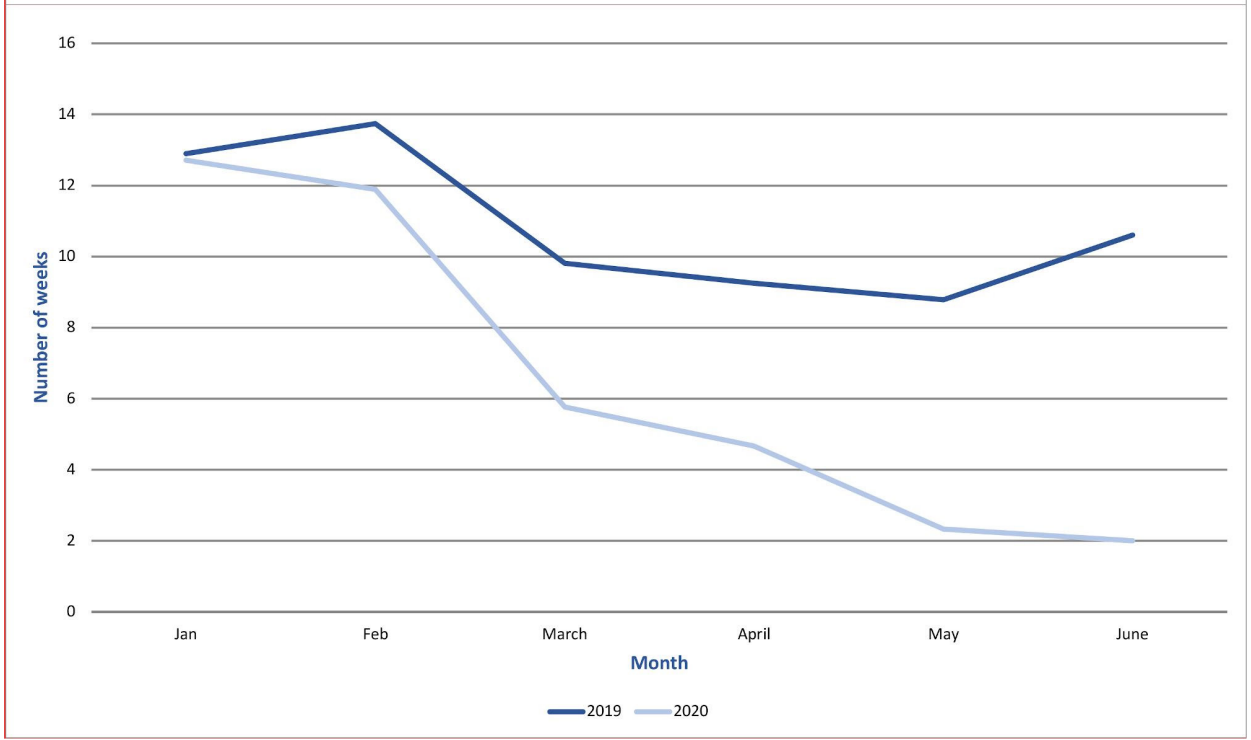

Figure 2 Mean wait time to be seen in clinic.

prepared quickly for the pandemic and COVID-19 patients, ${ }^{3}$ other areas were all but arrested. ${ }^{4}$ The vast majority of SNSDS referrals come from other specialties, such as orthopaedic surgeons or general paediatricians. With a reduced number of outpatient clinics, fewer patients were seen by the primary referring services, and therefore fewer children were referred to the SNSDS.

Often paediatric spinal conditions are first noticed by a teacher, sports instructor, friend or other adults who are in contact with the child. ${ }^{5}$ As lockdown was implemented and society's focus moved to staying at home to protect the NHS, children had fewer interactions with adults other than their immediate family. It therefore follows, that paediatric spinal conditions may have gone unnoticed during lockdown leading to reduced referrals from primary care.

Furthermore, patients' perception of front-line services changed from being places of safety to places of danger. ${ }^{6}$ Public health messages focused on the COVID-19 morbidity and mortality with very little emphasis on other health conditions within the population. This weighted coverage nurtured a perception of excessive risk by visiting a hospital or general practitioner which will have encouraged avoidance of hospitals ${ }^{6}$ leading to a lesser propensity to seek help for other health conditions.

Our data show a reduction in the mean waiting times for first clinical review. This could be misleading however, as at the time of data collection, there was still 60 patients awaiting to be seen. The patients who were able to be seen during the pandemic had uncomplicated spinal deformities. Due to shielding advice from the UK government, complex patients with severe syndromic or neuromuscular conditions either have not been offered a clinical appointment in the first place, or likely have postponed their appointment themselves in order to avoid exposure to the risk of contracting COVID-19. Therefore, these particularly vulnerable patients and possibly those with the greatest need for surgical input, will unfortunately be the patients who will have to wait the longest for their initial appointments, and therefore be further disadvantaged due to the COVID-19 pandemic.

Contributors MN: data collection and analysis. EG: expert opinion. AIT: data analysis, expert opinion, senior author.

Funding The authors have not declared a specific grant for this research from any funding agency in the public, commercial or not-for-profit sectors. The APC was paid for by the Scoliosis Research Fund.

Competing interests None declared.

Patient and public involvement Patients and/or the public were not involved in the design, or conduct, or reporting, or dissemination plans of this research.

Patient consent for publication Not required.

Provenance and peer review Not commissioned; externally peer reviewed.

Open access This is an open access article distributed in accordance with the Creative Commons Attribution Non Commercial (CC BY-NC 4.0) license, which permits others to distribute, remix, adapt, build upon this work non-commercially, and license their derivative works on different terms, provided the original work is properly cited, appropriate credit is given, any changes made indicated, and the use is non-commercial. See: http://creativecommons.org/licenses/by-nc/4.0/.

ORCID iD

Matthew Newman http://orcid.org/0000-0002-7265-1529

\section{REFERENCES}

1 Spinelli A, Pellino G. COVID-19 pandemic: perspectives on an unfolding crisis. Br J Surg 2020;23.

2 Green P. Risks to children and young people during covid-19 pandemic. BMJ 2020;369:m1669.

3 Adamson J, Bird C, Edgworth K, et al. Not just little adults: preparing a children's emergency department for COVID-19. Emerg Med J 2020:emermed-2020-209904.

4 Teoh JY-C, Ong WLK, Gonzalez-Padilla D, et al. A global survey on the impact of COVID-19 on urological services. Eur Urol 2020;78:265-75.

5 Adobor RD, Riise RB, Sørensen R, et al. Scoliosis detection, patient characteristics, referral patterns and treatment in the absence of a screening program in Norway. Scoliosis 2012;7:18.

6 Deerberg-Wittram J, Knothe C. Do not stay at home: we are ready for you. NEJM Catal 2020:1-7. 